
\title{
28 Research Square \\ Effect of Lighting Illuminance and Color Temperature on Mental Workload in Office Setting
}

Jiayi Bao

School of Biological Science and Medical Engineering, Beihang University

Xinbo Song ( $\square$ bjy5700@163.com )

Beijing Aeronautical Technology Research Center

Yan Li

School of Biological Science and Medical Engineering, Beihang University

Yinjie Bai

School of Biological Science and Medical Engineering, Beihang University

Qianxiang Zhou

School of Biological Science and Medical Engineering, Beihang University

\section{Research Article}

Keywords: Color temperature, Illuminance, Mental workload, Electroencephalogram

Posted Date: April 21st, 2021

DOI: https://doi.org/10.21203/rs.3.rs-436975/v1

License: (c) (i) This work is licensed under a Creative Commons Attribution 4.0 International License. Read Full License

Version of Record: A version of this preprint was published at Scientific Reports on July 27th, 2021. See the published version at https://doi.org/10.1038/s41598-021-94795-0. 


\section{Abstract}

The mental workload of subjects was tested in different lighting conditions, with color temperature ranging from $3000 \mathrm{~K}$ to $6500 \mathrm{~K}$ and illuminance $300 \mathrm{Ix}$ to $1000 \mathrm{Ix}$. We used both psychological and physiological responses for evaluation. The former was based on the NASA-TLX scores, and the latter was based on EEG P3b analysis of event-related potentials with the "oddball" paradigm experimental task. Results show that the $\mathrm{P} 3 \mathrm{~b}$ amplitudes are significantly affected by color temperature $(P=0.009)$ and illuminance $(P=0.038)$ levels. Office environment with $3000 \mathrm{~K}$ color temperature and $750 \mathrm{~lx}$ illumination, which exerts the lowest mental workload, is the most suitable for working. However, the interaction between color temperature and illuminance in affecting the mental workload of participants is not clear. This work provides more appropriate lighting choices with color temperature and illuminance in order to reduce people's mental workload in office setting.

\section{Introduction}

The effects of lighting on health and productivity have raised the level of concern in recent years, as people are spending more and more time in artificial light conditions in their everyday lives. Research has reported that artificial light had diverse and complex effects on humans, not only affecting vision, but also circadian rhythms ${ }^{1}$. Furthermore, it also has something to do with seasonal bodily function, physiological activity levels, and mood, etc.

Among all the features of light, color temperature and illuminance have the most important influence on human perception. The illuminance is defined as the luminous flux per square meter, in units of lux (Ix). The color temperature of a lamp equals the thermal temperature that an idealized black body would be required to assume to produce the same color as the lamp, in units of $\mathrm{K}^{2}$. Kruithof proposed a diagram which defined comfortable lighting conditions by combining illuminance and correlated color temperature ${ }^{3}$. Even though there is not enough evidence to support his study, the idea is regarded as pioneering in the field of lighting characteristics. Based on Kruithof's diagram, a lot of research have been carried out, focusing on adjusting the the boundary of comfortable lighting conditions. Kakitsuba proposed a new diagram of comfortable lighting illuminance and color temperature for psychological and physiological responses ${ }^{4}$. Besides, as a physiological response, electroencephalogram (EEG) is extensively applied to exploring the effect of lighting conditions on cognition ${ }^{5-10}$.

Attention and memory tasks were chosen as the cognitive tasks in the present study, for attention is one of the most fundamental features of our conscious performance in daily life ${ }^{11-12}$. Among different aspects of attention, sustained attention was selected to assess mental workload under specific combinations of illuminance and color temperature. Sustained attention involves the ability to maintain concentration on continuous tasks or information sources ${ }^{13-14}$. Thakral et al. and Lee et al. demonstrated that sustained attention is influential to neural activity in the parietal brain region ${ }^{15-16}$. 
In previous studies, the effects of color temperature on sustained attention were measured using various tasks, such as word repetition ${ }^{17}$, the Chu Attention Test ${ }^{18}$, short-term memory recall ${ }^{19}$, the Paced Visual Serial Addition Task ${ }^{20}$, the Numerical Verification Task ${ }^{21-22}$. It was shown that lighting with warm-white color temperature usually results in better cognitive performance. Chellappa demonstrated that higher color temperature is associated with faster reaction times in attention-related tasks ${ }^{20}$. Kocaoğlu found that $4000 \mathrm{~K}$ significantly increases errors of commission and the number of errors, while $6500 \mathrm{~K}$ is more appropriate for university learning environments ${ }^{23}$. In addition, Min reported that conditions of higher illuminance markedly led to lower parietal tonic EEG alpha activity and longer reaction times, comparison to other illuminance conditions ${ }^{24}$. Low-level illuminance often contributes to higher performance appraisals and better long term memory rate ${ }^{25-26}$, while high-level illuminance tend to make people less sleepy and more energetic ${ }^{27}$.

However, there is little information in open literature about the effect of combinations of illuminance and color temperature on mental workload. Therefore, it can be hypothesized that there exists some interaction between illumination and color temperature which would affect mental workload as well as lighting comfort. The purpose of the present study is to investigate the effects of illuminance and color temperature on mental workload by EEG, and to find appropriate lighting conditions for office environment.

\section{Results}

Subjective assessments. The NASA-TLX scores of different lighting conditions are described in Fig. 1. The results indicate that the lowest score is obtained at the color temperature of $3000 \mathrm{~K}$ and the illuminance of $750 \mathrm{~lx}$. However, there is no significant main effect result neither about the illuminance nor the color temperature. The interaction effect between illuminance and color temperatures is also not significant. A part of the mean subjective scores is shown in Table 1.

Table 1

An example of means \pm SD from physiological and psychological responds analysis in different lighting conditions $(n=12)$.

\begin{tabular}{|c|c|c|c|c|}
\hline Color temperature (K) & Illuminance (Ix) & Scores ${ }^{a}$ & Re - time ${ }^{b}$ & P3b - amp $(\mu v)^{c}$ \\
\hline 3000 & 300 & $71.4 \pm 14.6$ & $0.12 \pm 0.10$ & $0.83 \pm 0.30$ \\
\hline 3000 & 750 & $68.6 \pm 13.2$ & $0.4 \pm 0.22$ & $1.67 \pm 0.31$ \\
\hline 3000 & 1000 & $80.9 \pm 10.0$ & $0.52 \pm 0.24$ & $1.12 \pm 0.32$ \\
\hline \multicolumn{5}{|c|}{ a NASA-TLX scores as psychological response, lower scores predicted lower mental workload. } \\
\hline \multicolumn{5}{|c|}{ b The Min-Max-normalized response time, shorter re-time predicted lower mental workload. } \\
\hline
\end{tabular}


Behavioral performance. The average response time and the accuracy rate in the oddball experimental task were analyzed. The accuracy rate is not significantly influenced by illuminance or color temperature. However, the response time is significantly influenced by the illuminance according to the Min-Max Normalization scores. As shown in Fig. 2 (a) and Fig. 2 (b), the shortest response time occurs at illuminance of $300 \mathrm{~lx}$ with color temperature of $3000 \mathrm{~K}(\mathrm{P} \otimes 0.01)$. Moreover, when the color temperature is set at $6500 \mathrm{~K}$, the shortest response time occurs at $1000 \mathrm{~lx}(\mathrm{P} \otimes 0.01)$.

Physiological measurements. The amplitude and latency of P3b with different combinations of color temperature and illuminance were analyzed. The latency is not significantly influenced by the illuminance or color temperature. And there is no significant interaction between these factors regarding the P3b latency. For P3b amplitude, the analysis of variance on some electrode sites are listed in Table 2. The results indicate that amplitude is an important effect for the color temperature $(F[2,22]=5.102, P=0.009$ at $\mathrm{Cp} 4)$ and illuminance levels $(\mathrm{F}[2,22]=3.478, \mathrm{P}=0.038$ at $\mathrm{P} 4)$. However, no interaction of color temperature and illuminance levels has been observed $(F[4,44]=2.501, P=0.053)$.

Table 2

Significance analysis of the influence of color temperature and illuminance on P3b amplitude

\begin{tabular}{|lllc|}
\hline Source & Dependent variable & F & sig. \\
\hline Corrected model & C3 amplitude & 2.334 & .031 \\
\cline { 2 - 4 } & PZ amplitude & 2.222 & .039 \\
\cline { 2 - 4 } & Cp4 amplitude & 2.348 & .030 \\
\hline Color temperature $\times$ illuminance & C3 amplitude & 2.501 & .053 \\
\hline Color temperature & C3 amplitude & 3.191 & .049 \\
\cline { 2 - 4 } & PZ amplitude & 3.970 & .025 \\
\hline Illuminance & Cp4 amplitude & 5.102 & .009 \\
\hline
\end{tabular}

Examples of P3b amplitudes with different color temperatures under $750 \mathrm{~lx}$ illuminance are presented in Fig. 3, and the 2D topographic distributions of P3b are described in Fig. 4. An increase in the amplitudes indicates that the subject is becoming relaxed. In the case of $750 \mathrm{Ix}$, the results show that the P3b amplitude at $\mathrm{Cp} 4$ is obviously higher at $3000 \mathrm{~K}(\mathrm{P} 3000 \mathrm{~K}-4000 \mathrm{~K}=0.047 ; \mathrm{P} 3000 \mathrm{~K}-6500 \mathrm{~K}=0.001)$, meaning that the lowest mental workload occurs at $3000 \mathrm{~K}$.

Examples of P3b amplitudes with different illuminance levers under $3000 \mathrm{~K}$ color temperature are displayed in Fig. 5, and the 2D topographic distributions of P3b are described in Fig. 6. In the case of 
$3000 \mathrm{~K}$, the results show that the $\mathrm{P} 3 \mathrm{~b}$ amplitude at $\mathrm{P} 4$ is significantly higher at $750 \mathrm{~lx}(\mathrm{P} 750 \mathrm{~lx}-300 \mathrm{~lx}=$ $0.001 ; P 750 \mathrm{~lx}-1000 \mathrm{~lx}=0.001)$, meaning that the lowest mental workload occurs at $750 \mathrm{~lx}$. The means \pm SD of P3b amplitudes with $3000 \mathrm{~K}$ are listed in Table 1 .

\section{Discussion}

The effect of lighting illuminance and color temperature on mental workload was investigated in the present study by subjective assessment, behavioral performance and EEG analysis. However, no significant interaction between illuminance and color temperature on mental workload has been found from all aspects of the data, as is outlined in Table 2. These results are not consistent with the hypothesis that there is some interaction between illumination and color temperature in terms of mental workload,as well as lighting comfort.

Neither illuminance levels nor color temperature shows significant affect in NASA-TLX scores. The principal reason may be individual differences and the limited sample size.

As indicated in Fig. $2(a)$ and (b), when the color temperature is set at $3000 \mathrm{~K}$, the response time will be delayed as the illuminance increases, which is consistent with the previous study ${ }^{24}$.Yan et al also found learning efficiency was higher with $2700 \mathrm{~K}$ color temperature and $300 \mathrm{~lx}$ illuminance ${ }^{28}$. When the color temperature is set at $6500 \mathrm{~K}$, the shortest response time occurs at $1000 \mathrm{~lx} .6500 \mathrm{~K}$ called "cool temperature" can make people alert and concentrate when the illuminance improved. Chellappa found that light at $6500 \mathrm{k}$ led to significantly faster reaction time in the sustained attention task ${ }^{20}$.

As described in Fig. 3 and Fig. 5, P3b amplitudes are observably influenced by color temperature and illuminance. When the illuminance is $750 \mathrm{~lx}$, the highest amplitude occurs at $3000 \mathrm{~K}$. Manav demonstrated that $2700 \mathrm{~K}$ was suggested for 'relaxation' and 'saturation evaluation' 29 . This may indicate that around $3000 \mathrm{~K}$ is a low mental workload color temperature. With $3000 \mathrm{~K}$ color temperature, the highest amplitude occurs at $750 \mathrm{~lx}$. In an extremely bright or dark environment, we can't concentrate so that we cannot complete the memory task well. This is same as the relationship between arousal and attention. The ability to focus attention effectively is non-linear with arousal. It is roughly like an inverted U-shaped function ${ }^{30}$.

Another purpose of the present study is to find more suitable lighting conditions for the office environment. As described in Table 1, through the above analysis of EEG data, it can be seen that a combination of $3000 \mathrm{~K}$ color temperature and $750 \mathrm{~lx}$ illumination produced the lowest mental workload. This is also consistent with the results of subjective assessment.

\section{Conclusion}

Under different lighting conditions of color temperature (3000 K / $4000 \mathrm{~K} / 6500 \mathrm{~K}$ ) and illuminance (300 Ix / 750 Ix / 1000 lx), twelve postgraduates participated in sustained attention task experiments. In 
addition, NASA-TLX scores as psychological responses, the accuracy and response time as behavioral performance and EEG data as physiological responses were recorded continuously in the experiment. The results show that the combination of $3000 \mathrm{~K}$ color temperature and $750 \mathrm{Ix}$ illumination, which has the lowest mental workload, is better suited to office setting. However, no significant interaction between color temperature and illumiance for the mental workload was found.

This study is only for healthy students. Vision problems such as myopia, hyperopia, astigmatism, etc. may lead to deviations in test results. In addition, compared with the background lighting conditions, the influence of the screen stimulus light on the experimental results may be more remarkable. How to set the screen lighting condition to minimize its impact on experimental results needs further research.

\section{Methods}

Subjects. Twelve postgraduates from Beihang University participated as subjects for this study. All the participants (male, age,23-27 year, mean 24.3) were right-handed and possessed normal vision. Caffeinated drinks, medication, smoking, and exercise were prohibited before the experiment for a week. Meanwhile, all participants reported that they slept between six and eight hours in the past night. The experimental protocol was approved by the Ethics Committee of Beihang University, all methods were carried out in accordance with relevant guidelines and regulations. All research activities were adhered to the principles of the Declaration of Helsinki, and written informed consent was obtained from the participants before the experiment.

Procedure. The experimental office (dimensions: $10 \mathrm{~m} \mathrm{~L} \times 4.5 \mathrm{~m} \mathrm{~W} \times 3.0 \mathrm{~m} \mathrm{H}$ ) is shown in Fig. 7. The air temperature was about $25^{\circ} \mathrm{C}$. Black curtains were used to exclude natural daylight. The suspended ceiling was white. Walls were painted light white, and the floor was light gray brick. The lighting system was supplied by nine luminaires (TBS 168/363 M5) recessed in the suspended ceiling. The total number of the fluorescent lamps (Philips TLD/36W/830; Philips TLD/36W/840; Philips TLD/36W/865) was 27. Each of them was connected to dimmable electronic ballasts. It was regulated by light master 100 lighting control system. The lighting system was designed to provide nine different lighting scenarios, and it was numbered on a remote control. The system could be adjusted to maintain a constant illumination level of 300, 750 and $1000 \mathrm{Ix}$ on the working surface while 3000,4000 and $6500 \mathrm{~K}$ color temperature could be created separately. Illuminance values were measured by an LMT P01704 Luxmeter and an LMT Luminance Meter L1009. This experiment was in a random order to avoid the influence which brings by the sequence of the experiment. Each experiment consisted of 9 trials of 25 min each, followed by breaks of $30 \mathrm{~min}$ i.e. enough time for rest and adaptation to the new illumination.

The target stimulus is presented On the PC (Lenovo) screen in front of the participant. In this task, all participants were required to practice the task until they were skilled at it when the accuracy rate was 80 percent or more. The participants were required to focus, to do their best to complete the task as fast as possible, and to ensure the accuracy of their answers. A small reward was given for good performance. 
All participates had 30 minutes to adapt to the new environment. After that, the participants need to accomplish the block of the task. Each subject should fill in the NASA Task Load Index (NASA-TLX, NASA) after each block, which was used to evaluate mental workload regarding participants' subjective feelings, the higher score, the greater mental workload ${ }^{31}$. The experiments were conducted from 8:00 to 11:30 and from 14:00 to 18:30. The participant could finish the task in 0.5 hours and have a rest for 0.5 hours.

EEG task and data recording. Computerized task was chosen for this experiment because the office people under artificial lighting get the majority of information from display terminals in modern life. The experimental task was an "oddball" paradigm controlled by E-prime software (Psychology Software Tools, Inc., Pittsburgh, PA) that placed demands on sustained attention and memory. In this paradigm, the target stimulus was a five-digit number, and the non-target stimulus was a two-digit number. There were 120 target stimuli and 480 non-target stimuli. Between every two target stimuli, there were about two to six non-target stimuli. The presentation time for each target or non-target stimulus was $600 \mathrm{~ms} .3 .5 \mathrm{~s}$ were allowed for responding after the offset of each stimulus presentation. An experimental block, corresponding to one illuminance and color temperature combination, took about $25 \mathrm{~min}$. Subjects were instructed to memorize each target stimulus figure as soon as possible. Then, they were required to enter the figure in a form after it disappeared on the computer. If a non-target stimulus appeared, participants were asked to identify it as such and to press the "Enter" button after it disappeared.

The task flow diagram is shown in Fig. 8. In the task flow, the start signal will occur in the middle of the computer screen. The '+' signal means you should focus and the sequence of numbers will take place in the center of the screen. The current image is $1280 \times 1024$ pixels.

EEG activity was recorded at the C3 / Cz / C4, P3 / Pz / p4, and Cp3 / Cpz / Cp4 electrode sites, and was referred to linked earlobes, with a forehead ground and impedances of $5 \mathrm{k} \Omega$ or less. Additional electrodes were placed at the outer left canthus and below the left eye to measure electrooculography (EOG) activity with a bipolar recording. The band pass was $0.1-30 \mathrm{~Hz}$ (slope $=6 \mathrm{~dB} /$ octave), and EEG was digitized online at a sampling frequency of $1 \mathrm{kHz}$. The baseline was $100 \mathrm{~ms}$ pre-stimulus. Waveforms were averaged off-line, such that trials on which the EEG or EOG exceeded $\pm 150 \mathrm{mV}$ were rejected automatically. Further, single-trial data were subjected to an EOG correction procedure to remove any remaining artifact. The CURRY 7.0 software was used to record the dates. The SynAmps amplifier was used for collecting EEG signals. The data analyses and the display of the results were performed using the Neuroscan software. During the experiment, the participants' response times and accuracy rates were recorded by E-prime.

P3b analysis. In the following we focused on the P3b wave which was elicited by the target stimuli. P3b amplitude and latency were used to infer mental workload under different conditions of color temperature and illumination. The time window used to extract it was $900 \mathrm{~ms}$ long, starting $100 \mathrm{~ms}$ before the target stimulus onset and ending $800 \mathrm{~ms}$ after. The mean amplitude and latency were calculated at every electrode site (C3 / Cz / C4, Cp3 / Cpz / Cp4, and P3 / Pz / P4). As indicators of high mental workload, a reduced $\mathrm{P} 3 \mathrm{~b}$ amplitude and increase latency were found $\mathrm{d}^{32}$. 
Statistics analysis. The results are reported as the mean \pm standard deviation (SD) and boxplots. Data were analyzed with a repeated measures analysis of variance (ANOVA), which included two withinsubjects factors labeled as "illuminance" (300 lx / $750 \mathrm{~lx} / 1000 \mathrm{~lx}$ ) and "color temperature" (3000 K / $4000 \mathrm{~K} / 6500 \mathrm{~K})$. The means were compared by Duncan's test at a probability of $95 \%$. Statistical analyses were performed using SPSS Statistics 17.0 (SPSS, Inc., Chicago, IL, USA). Because of limited numbers of participants, individual differences influenced the raw results. To reduce this influence, the Min-Max normalization method was used to analyze the NASA-TLX and behavioral performance data.

\section{Declarations}

\section{Data availability}

The data that support the findings of this study are available from the corresponding author upon reasonable request.

\section{Acknowledgements}

This study was supported by Grant-in-aid for scientific research from the National Natural Science Foundation of China (No. 11772038).

\section{Author contributions}

X.S. designed the study, J.B. performed the data analysis and wrote the manuscript. Y.B. performed the debugging and measurement of experimental parameters and collected data. L.Y. and Q.X. revised the manuscript. All authors reviewed the manuscript.

\section{Competing interests}

The authors declare no competing interests.

\section{Additional information}

Correspondence and requests for materials should be addressed to X.S.

\section{References}

1. Stevens, R. G. et al. Meeting report: the role of environmental lighting and circadian disruption in cancer and other diseases. Environmental health perspectives. 115 (9), 1357-1362 https://doi.org/10.1289/ehp.10200 (2007).

2. Wessolowski, N., Koenig, H., Schulte-Markwort, M. \& Barkmann, C. The effect of variable light on the fidgetiness and social behavior of pupils in school. Journal of Environmental Psychology. 39, 101108 https://doi.org/10.1016/j.jenvp.2014.05.001 (2014). 
3. Kruithof, A. A. Tubular luminescence lights for general illumination. Philips Tech. Rev. 6 (3), 65-96 (1941).

4. Kakitsuba, N. Comfortable indoor lighting conditions evaluated from psychological and physiological responses. Leukos. 12 (3), 163-172 https://doi.org/10.1080/15502724.2015.1061945 (2016).

5. Ermolaev, R. Y. \& Kleinman, D. The effect of background illumination on pattern onset visual evoked potentials. Electroencephalography and clinical Neurophysiology. 55 (5), 546-556 https://doi.org/10.1016/0013-4694(83)90165-7 (1983).

6. Yagi, A., Imanishi, S. \& Konishi, H. Brain potentials associated with eye fixations during visual tasks under different lighting systems. Ergonomics. 41 (5), 670-677 https://doi.org/10.1080/001401398186838 (1998).

7. Noguchi, H. \& Sakaguchi, T. Effect of illuminance and color temperature on lowering of physiological activity. Applied human science. 18 (4), 117-123 https://doi.org/10.2114/jpa.18.117 (1999).

8. Maher, A. M. et al. Effect of luminance level on electro-encephalogram alpha-wave synchronisation. Medical and Biological Engineering and Computing. 39 (6), 672-677 https://doi.org/10.1007/bf02345440 (2001).

9. Shin, J. Y., Chun, S. Y. \& Lee, C. S. Analysis of the effect on attention and relaxation level by correlated color temperature and illuminance of LED lighting using EEG signal. Journal of the Korean Institute of Illuminating and Electrical Installation Engineers. 27 (5), https://doi.org/10.5207/JIEIE.2013.27.5.009 (2013).

10. Park, J. Y. et al. Illumination influences working memory: an eeg study. Neuroscience. 247 (Complete), 386-394 https://doi.org/10.1016/j.neuroscience.2013.05.016 (2013).

11. Sohlberg, M. M. \& Mateer, C. A. Introduction to cognitive rehabilitation: Theory and practice. Guilford Press. https://sci-hub.tf/10.1016/0028-3932(90)90117-7 (1989).

12. Sohlberg, M. M. \& Mateer, C. A. (eds) Cognitive rehabilitation: An integrative neuropsychological approach. Guilford Press. https://sci-hub.tf/10.1093/brain/awg003 (2001).

13. Cimprich, B. A theoretical perspective on attention and patient education. Advances in Nursing Science. 14 (3), 39-51 https://doi.org/10.1097/00012272-199203000-00007 (1992).

14. Solso, R. L., MacLin, M. K. \& MacLin, O. H. Cognitive psychology, 7th ed. Cognitive psychology. Pearson Education New Zealand. https://psycnet.apa.org/record/2004-19852-000 (2005).

15. Thakral, P. P. \& Slotnick, S. D. The role of parietal cortex during sustained visual spatial attention. Brain Res. 1302, 157-166 https://doi.org/10.1016/j.brainres.2009.09.031 (2009).

16. Lee, J., Ku, J., Han, K., Park, J., Lee, H., Kim, K. R... Kim, S. I. rTMS over bilateral inferior parietal cortex induces decrement of spatial sustained attention. Frontiers in human neuroscience, 7, 26. https://doi.org/10.3389/fnhum.2013.00026 (2013).

17. LaPointe, L. L. et al. The effects of auditory distraction on visual cognitive performance in multiple sclerosis. Journal of Neuro-ophthalmology. 25 (2), 92-94 https://doi.org/https://scihub.tf/10.1097/01.wno.00001611660.91272.18 (2005). 
18. Huang, R. H., Lee, L., Chiu, Y. A. \& Sun, Y. Effects of correlated color temperature on focused and sustained attention under white LED desk lighting. Color Research \& Application. 40 (3), 281-286 https://doi.org/10.1002/col.21885 (2015).

19. Knez, I. \& Hygge, S. Irrelevant speech and indoor lighting: effects on cognitive performance and selfreported affect. Applied Cognitive Psychology: The Official Journal of the Society for Applied Research in Memory and Cognition. 16 (6), 709-718 https://doi.org/10.1006/jevp.2001.0222 (2002).

20. Chellappa, S. L. et al. Non-visual effects of light on melatonin, alertness and cognitive performance: can blue-enriched light keep us alert? PloS one. 6 (1), e16429 https://doi.org/10.1371/journal.pone.0016429 (2011).

21. Davis, R. G. \& Garza, A. Task lighting for the elderly. Journal of the illuminating Engineering Society. 31 (1), 20-32 (2002).

22. Yamagishi, M., Yamaba, K., Kubo, C., Nokura, K. \& Nagata, M. Effects of LED lighting characteristics on visual performance of elderly people. Gerontechnology. 7 (2), 243 https://doi.org/10.4017/GT.2008.07.02.180.00 (2008).

23. Kocaoğlu, R. The Effects of correlated color temperature on sustained attention and mood of university students in learning environments (Doctoral dissertation, Bilkent University)(2015).

24. Min, B. K., Jung, Y. C., Kim, E. \& Park, J. Y. Bright illumination reduces parietal EEG alpha activity during a sustained attention task. Brain Res. 1538 (22), 83-92 https://doi.org/10.1016/j.brainres.2013.09.031 (2013).

25. Baron, R. A., Rea, M. S. \& Daniels, S. G. Effects of indoor lighting (illuminance and spectral distribution) on the performance of cognitive tasks and interpersonal behaviors: The potential mediating role of positive affect. Motivation and emotion. 16 (1), 1-33 https://doi.org/10.1007/BF00996485 (1992).

26. Jung, H. C., Kim, J. H. \& Lee, C. W. The effect of the illuminance of light emitting diode (LED) lamps on long-term memory. Displays. 49, 1-5 https://doi.org/10.1016/j.displa.2017.05.001 (2017).

27. Smolders, K. C., De Kort, Y. A. \& Cluitmans, P. J. M. A higher illuminance induces alertness even during office hours: findings on subjective measures, task performance and heart rate measures. Physiol. Behav. 107 (1), 7-16 https://doi.org/10.1016/j.physbeh.2012.04.028 (2012).

28. Yong-hong, Y. A. N., Ning, Y. A. N., Yang, G. U. A. N. \& Heng-zhi, Z. E. N. G. Impact on brain wave rhythm and learning efficiency by color temperature of artificial light sources. Journal of Civil, Architectural \& Environmental Engineering. (1), 76-79 https://doi.org/10.11835/j.issn.16744764.2012.01.015 (2015).

29. Manav, B. An experimental study on the appraisal of the visual environment at offices in relation to colour temperature and illuminance. Building and environment. 42 (2), 979-983 https://doi.org/10.1016/j.buildenv.2005.10.022 (2007).

30. Purves, D. et al. Cognitive neuroscience. Sunderland: Sinauer Associates, Inc(2008).

31. Hart, S. G. \& Staveland, L. E. Development of NASA-TLX (Task Load Index): Results of empirical and theoretical research. In Advances in psychology (Vol. 52, pp. 139-183). North-Holland. 
https://doi.org/10.1016/S0166-4115(08)62386-9 (1988).

32. Käthner, I., Wriessnegger, S. C., Müller-Putz, G. R., Kübler, A. \& Halder, S. Effects of mental workload and fatigue on the P300, alpha and theta band power during operation of an ERP (P300) braincomputer interface. Biological psychology. 102, 118-129 https://doi.org/10.1016/j.biopsycho.2014.07.014 (2014).

\section{Figures}

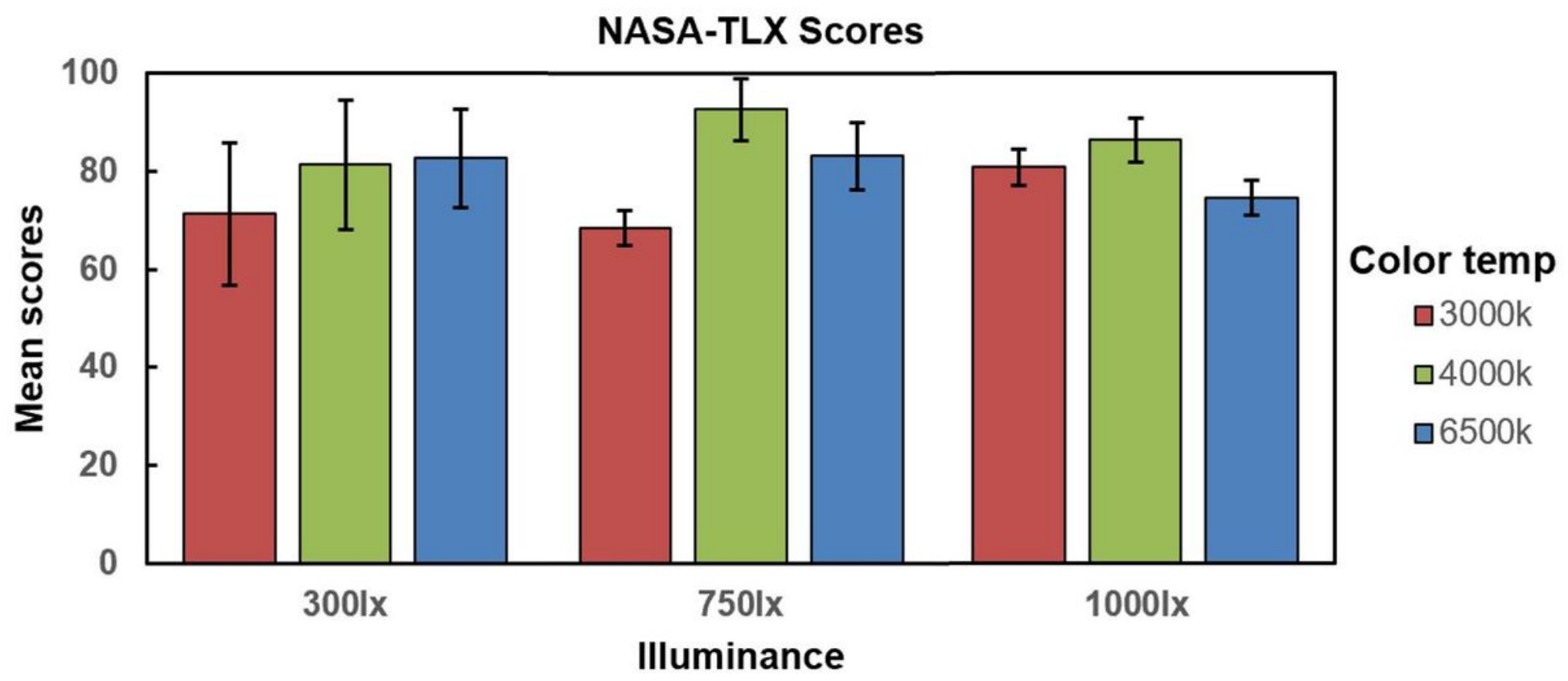

\section{Figure 1}

NASA-TLX scores (mean \pm SD) under different conditions of color temperatures $(3000 \mathrm{~K} / 4000 \mathrm{~K} / 6500$ K) and illuminance (300 lx / $750 \mathrm{~lx} / 1000 \mathrm{~lx}$ ) levels. There was no significant main effect result neither about the illuminance nor the color temperature. The interaction effect between illuminance and color temperatures also not significant. 

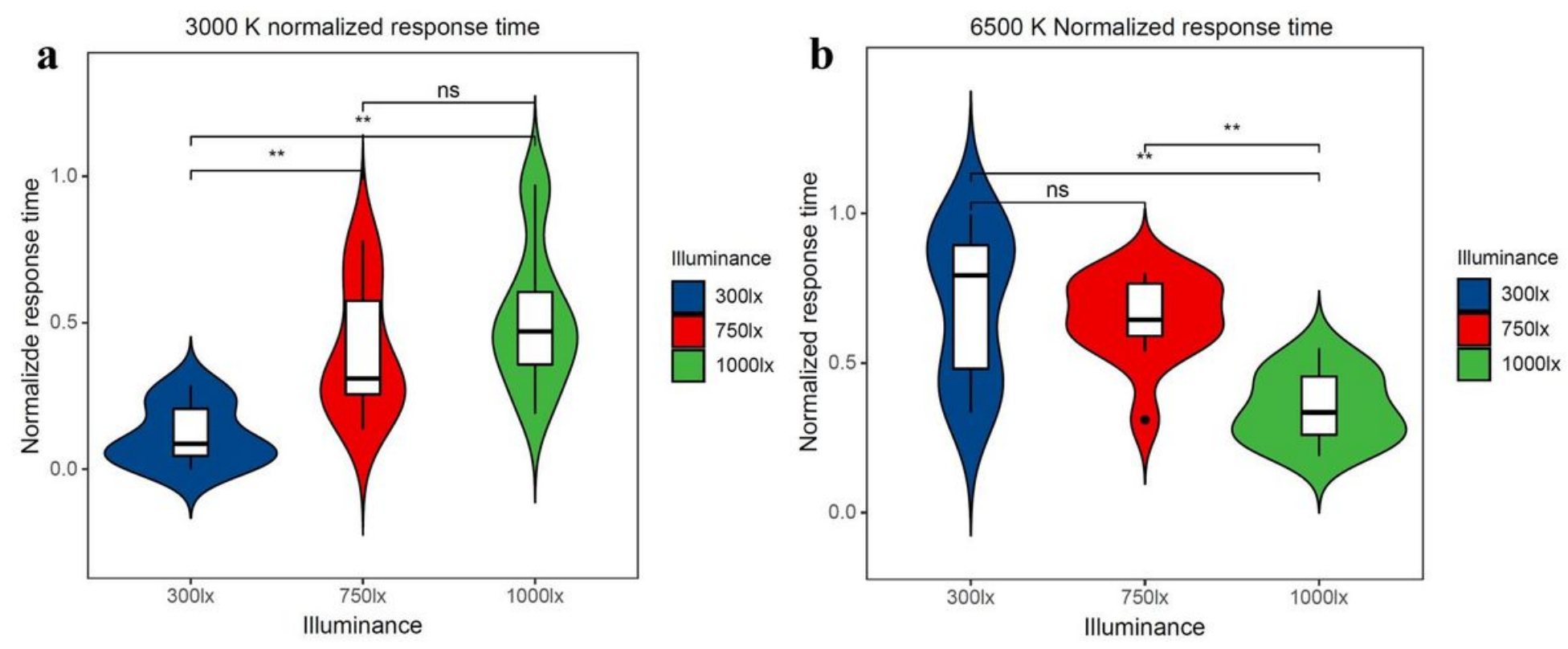

Figure 2

(a) The Min-Max-normalized response time of the experiment task under different illuminance in $3000 \mathrm{~K}$ color temperature. (b) The Min-Max-normalized response time of the experiment task under different illuminance in $6500 \mathrm{~K}$ color temperature. The upper diagram shown that the response times of $3000 \mathrm{~K}-$ $300 \mathrm{Ix}$ and $6500 \mathrm{~K}-1000 \mathrm{Ix}$ were significantly lower than others $(*, P<0.05 ; * \star, P<0.01)$

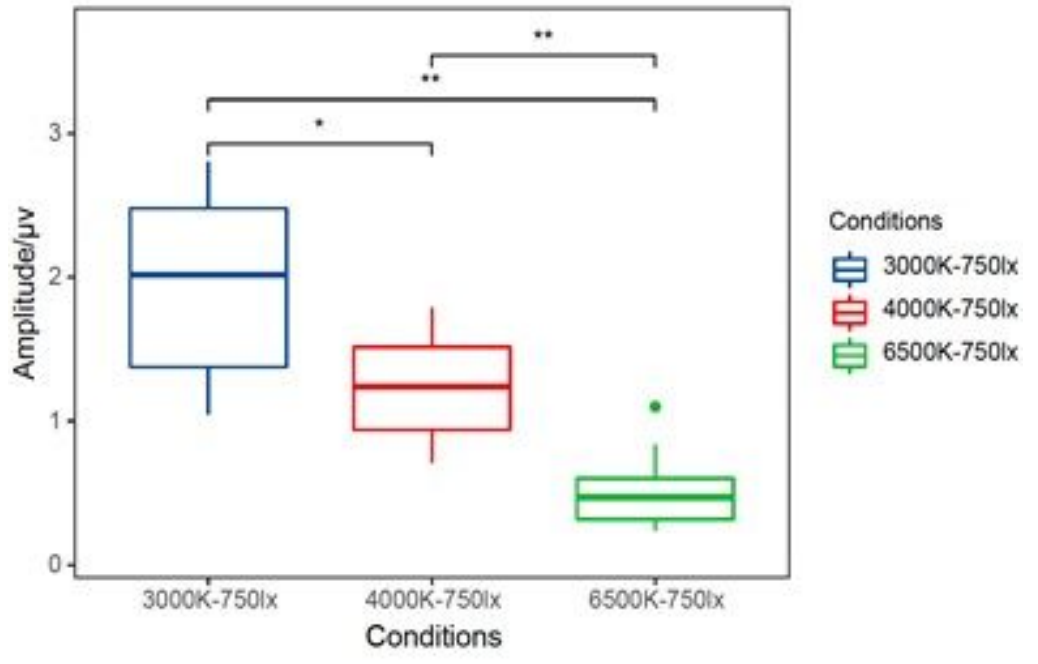

\section{Figure 3}

An example of P3b amplitudes with different color temperatures under 750 Ix illuminance at Cp4 electrode ( ${ }^{*}, \mathrm{P}<0.05 ; * \star, P<0.01$ ). The amplitude at $3000 \mathrm{~K}$ was significantly higher, indicating the lowest mental workload occurred at $3000 \mathrm{~K}$. 


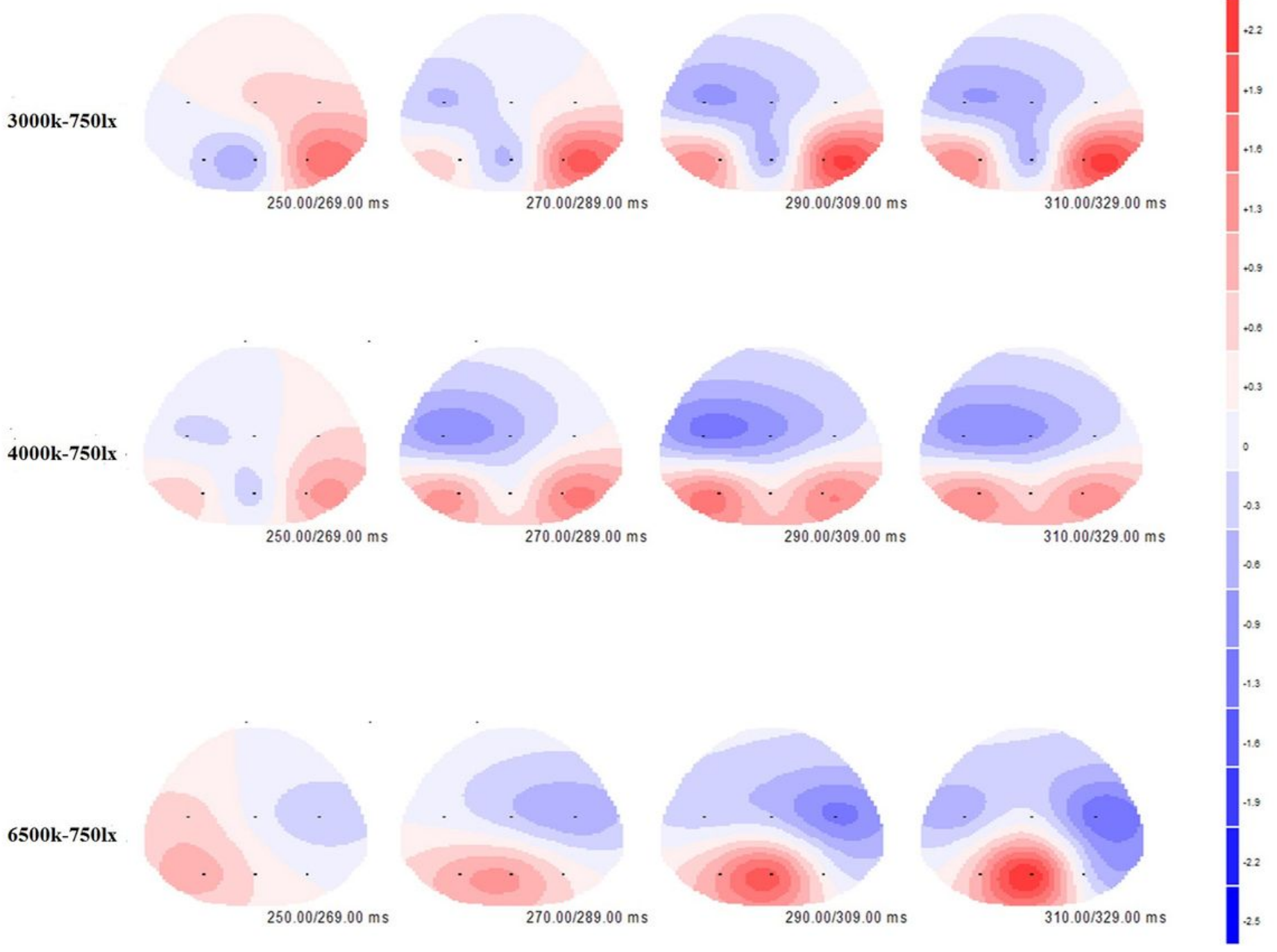

\section{Figure 4}

An example of P3b amplitudes with different color temperatures under 750 Ix illuminance at Cp4 electrode ( $\left.{ }^{*}, \mathrm{P}<0.05 ; * \star, P<0.01\right)$. The amplitude at $3000 \mathrm{~K}$ was significantly higher, indicating the lowest mental workload occurred at $3000 \mathrm{~K}$. 


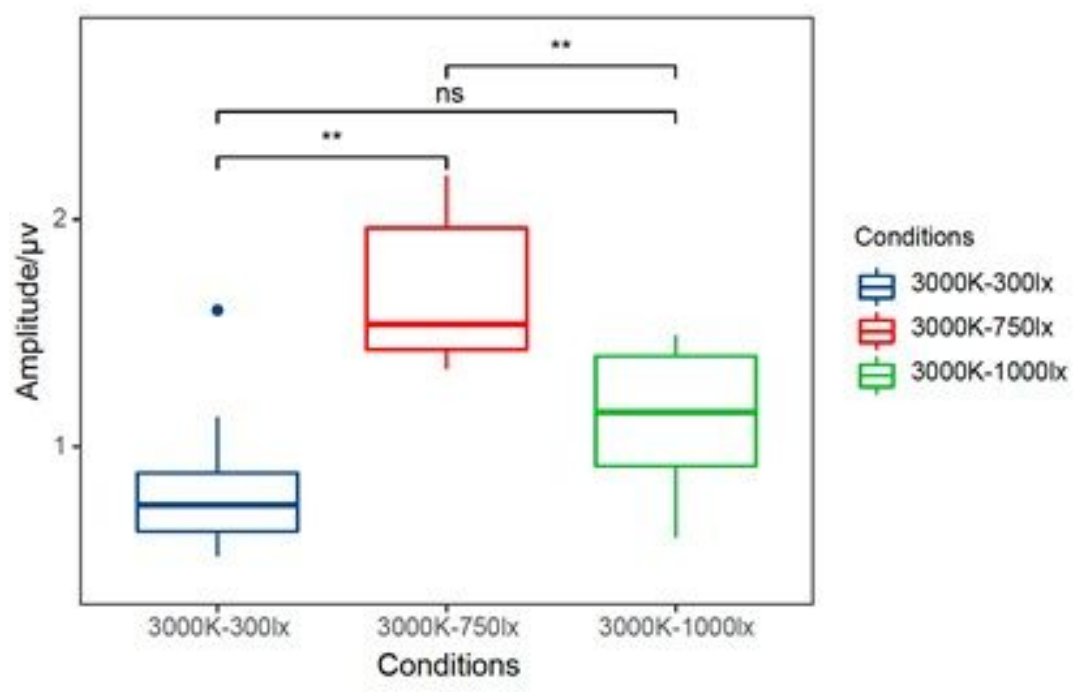

Figure 5

An example of P3b amplitudes with different illuminance levers under $3000 \mathrm{~K}$ color temperature at P4 electrode $(*, P<0.05 ; * \star, P<0.01)$. The amplitude at $750 \mathrm{~lx}$ was significantly higher, indicating the lowest mental workload occurred at $750 \mathrm{~lx}$. 


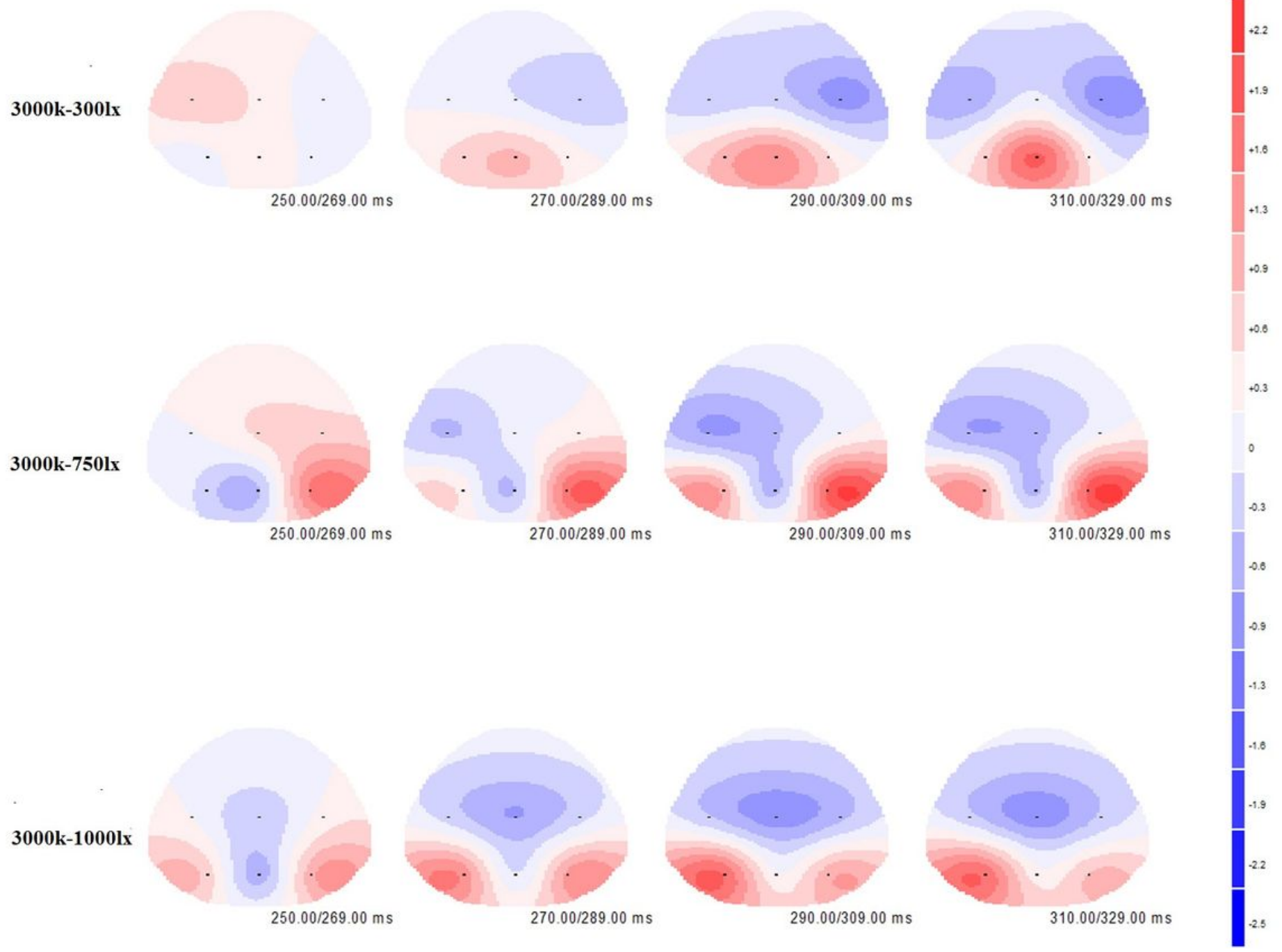

Figure 6

2D scalp topographic distributions of P3b with different illuminance levels (300 Ix/750 Ix/1000 Ix) under $3000 \mathrm{~K}$ color temperature. 


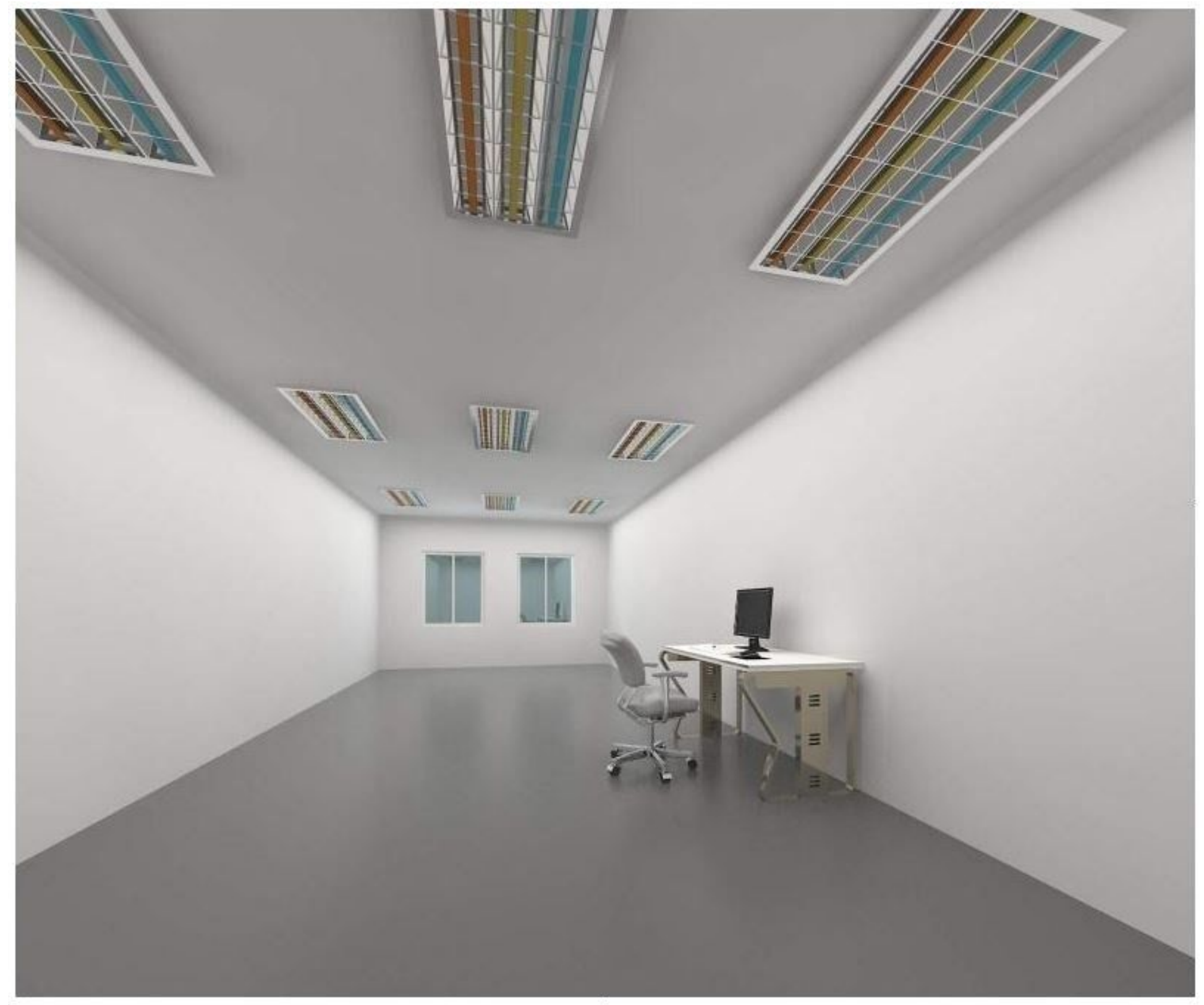

Figure 7

The laboratory setting which was installed nine controllable luminaires on the ceiling, and black curtains on the windows to separate with sunlight. 